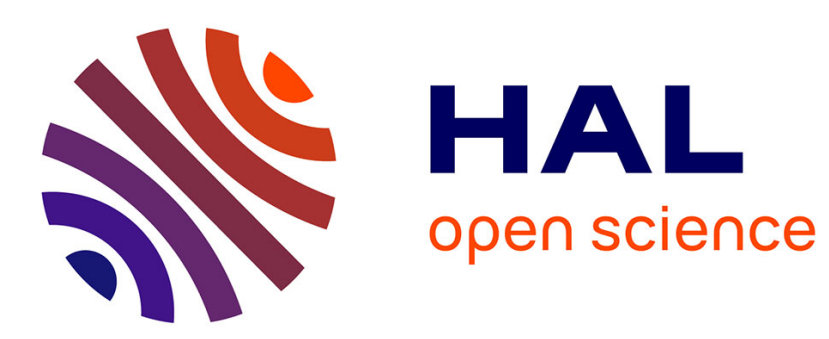

\title{
Interests of synchrotron radiation for internal stress analysis
}

\author{
J. Lebrun, P. Gergaud, V. Ji, M. Belassel
}

\section{To cite this version:}

J. Lebrun, P. Gergaud, V. Ji, M. Belassel. Interests of synchrotron radiation for internal stress analysis. Journal de Physique IV Proceedings, 1994, 04 (C9), pp.C9-265-C9-268. 10.1051/jp4:1994946 . jpa00253507

\section{HAL Id: jpa-00253507 https://hal.science/jpa-00253507}

Submitted on 1 Jan 1994

HAL is a multi-disciplinary open access archive for the deposit and dissemination of scientific research documents, whether they are published or not. The documents may come from teaching and research institutions in France or abroad, or from public or private research centers.
L'archive ouverte pluridisciplinaire HAL, est destinée au dépôt et à la diffusion de documents scientifiques de niveau recherche, publiés ou non, émanant des établissements d'enseignement et de recherche français ou étrangers, des laboratoires publics ou privés. 


\title{
Interests of synchrotron radiation for internal stress analysis
}

\author{
J.L. Lebrun, P. Gergaud, V. Ji and M. Belassel
}

ENSAM, LM3, URA 1219 du CNRS, 151 Bd de l'Hôpital, 75013 Paris, France

\begin{abstract}
The interest of the method of X-ray diffraction for residual stress measurement is in continuous progress due to the advances in theoretical research and the development of new equipment. Usually, the shift and broadening of a diffraction peak reveal respectively the macrostrain (or stress) and microstrain. The limits of the X-ray provided by classical tubes in laboratory are its low intensity, fixed wavelength and relatively poor optic and spectrum resolution. This paper is a review of the use and interest of the synchrotron radiation in internal stress or strain analysis.
\end{abstract}

\section{INTRODUCTION}

At the present time, the stress determination by diffraction method is the only one that gives information on both macro and micro stresses. It is evolving rapidly because of continuous advances both in theoretical and technological aspects [1]. After explaining the fundamentals of the method, this paper deals with the most important works conducted using synchrotron radiation for macro and micro stress analysis in different materials. We show the importance of this radiation in the stress determination at different scales of the metallurgical material by its high resolution, spectral and spatial resolutions .

\section{BASIS OF THE METHOD}

\subsection{General principles}

The principles of the method is to take as a strain gauge the interatomic spacing $d_{h k l}$ of a family of planes $(\mathrm{hkl})$. The variation $\Delta \mathrm{d}$, caused by residual stress, is measured from Bragg's law :

$\varepsilon=\Delta d / d=-\operatorname{cotg} \theta(\Delta \theta)$, where $\varepsilon$ is the strain and $\theta$ is the Bragg angle. This relationship shows that the shift $\Delta \theta$ of an X-ray diffraction line of a strained (hkl) family, increase with $\theta$, by $\operatorname{cotg} \theta$ factor.

\subsection{Macrostresses and microstresses :}

Three kinds of stresses can be conventionally defined, namely 1 st, 2 nd and 3 rd order [1,2]. First order stresses are those on the scale of a few grains, those of 2 nd order on the scale of one grain and those of 3rd the scale of a few interatomic distances. Residual stresses in general are the superposition of these three kinds of stress. This superposition is schematically illustrated in Figure 1. The three orders of stress have different effect on X-ray diffraction. For first order stresses, the uniform strain over one group of grains produces a global strain of the interatomic spacing $\varepsilon=\Delta \mathrm{d} / \mathrm{d}$ and hence the diffraction ring of the family of crystalline planes will move

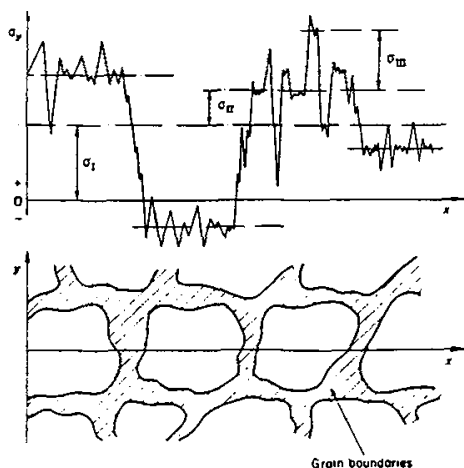

Figure 1: The three stress orders. 
The second order stresses produce different strains in each grain. In the case of materials with large grains, it gives diffraction spots which will be shifted from the mean diffraction ring. The consequences of third order stresses are fluctuations on a small scale around the mean value $\mathrm{d}_{0}$ and thus a broadening of the diffraction ring with small grains or a spreading of the diffraction spots with large grains. In the case of small grain size, when the diffraction ring is continuous, the effects of 2 nd and 3rd order stresses both lead to a broadening of the diffraction ring that can be analysed in terms of microstresses. The first order stresses are macrostresses. It is these stresses that, at present, primarily interest the mechanical engineer. It must be pointed out that the strain gauges give information only on these macrostresses.

\subsubsection{Principles of the Macrostress Method Determination:}

Macrostresses correspond to a strain, uniform in value over many grains, producing an overall variation $\varepsilon$, of the interatomic spacing. The link from the measured strains to the stresses $\sigma$ is made through the elastic stress-strain relationships. In applying these relationships to X-ray diffraction measurements, the following assumptions are necessary :

- The crystallites must have a linear elastic mechanical behaviour.

- The polycrystalline material must be quasi-isotropic. So the diffracting crystallite size must be small

enough to have a large number of diffracting crystallites without any preferential orientation

- The macroscopic state of stresses and strains must be homogeneous in all of the volume irradiated

by the $\mathrm{X}$-rays (no stress gradients).

In a general way, the measured strains are linked to the macroscopic stresses by the relation:

$\varepsilon_{\mathrm{ij}}=\mathrm{F}_{\mathrm{ij}} \sigma_{\mathrm{ij}}$, where the terms $\mathrm{F}_{\mathrm{ij}}$ are not tensor components, but mere coefficients for quasi-isotropic materials, for instance, these $F_{i j}$ coefficients depend only on the classical elastic constants $1 / 2 S_{2}$, and $S_{1}$ and the sample orientations angles $\phi$ and $\psi$ (figure 2 ). Thus, $F_{i j}=1 / 2 S_{2(h k l)} \rho_{3 i} \cdot \rho_{3 j}+S_{1(h k l)} \cdot \delta_{i j}$

with $\rho_{\mathrm{ij}}=\phi_{\mathrm{ik}} \psi_{\mathrm{kj}},\left(\rho_{\mathrm{ij}}, \phi_{\mathrm{ik}}, \psi_{\mathrm{kj}}\right.$ : transformation matrix components). With these assumptions, the strain $\varepsilon_{\phi \psi}$ can be written using the classical $\sin ^{2} \psi$ law, which is linear or elliptic.

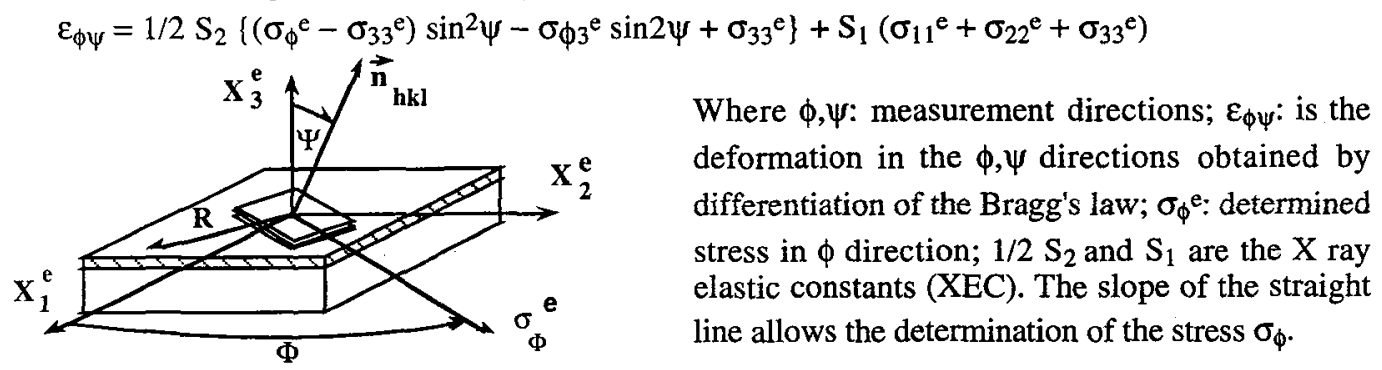

Figure 2: Definition of the measurement angles $\phi, \psi$.

\subsubsection{Limits of The Method}

The limitations of the method are directly related to the assumptions, listed above, of the $\sin ^{2} \psi$ law. The problems appear at (i) a metallurgical level (X-ray diffraction) as the grain size, the content of the second phase and cold working in the material and at (ii) a mechanical level (linearity of the $\sin ^{2} \psi$ law) which may appear in case of two phase alloys, high gradient and textures in material

\subsection{Synchrotron Application}

In the following presentation, the most works already done using synchrotron radiation can be classified by type order of stresses presented above: first, second and third order found in different types of material.

\subsubsection{First order stresses:}

This type of stresses comes from the incompatibility of the deformation at the macroscopic scale of the material. Several applications of synchrotron radiation have been developed using the wavelength variation, as for example stress gradient and X ray elastic constants of textured materials and which are needed for stress determination in materials.

For textured materials, XEC have been carried out on different planes located at the same $2 \theta$ Bragg angle [3]. This is possible using a continuous variable synchrotron radiation wavelength. On figure 3 the results have been compared with theoretical ones in a case of a cubic crystallography structure. This result enables our laboratory to make classical X ray measurements on other kinds of textured materials. 
In a case of high stress gradient, two formalisms have been developed using different diffracting planes with range of $\psi$ values, one using different monochromatic wavelengths [4,5] and a more recent one using Energy Dispersive diffraction (EXRD) [6,7]. This last method has been applied in a case of cold rolled nickel plate and ground steel. The results presented on figure 4 show a strongly non-linear variation of stresses in a surface layer about $2 \mu \mathrm{m}$ thick. This method is a fully non-destructive.

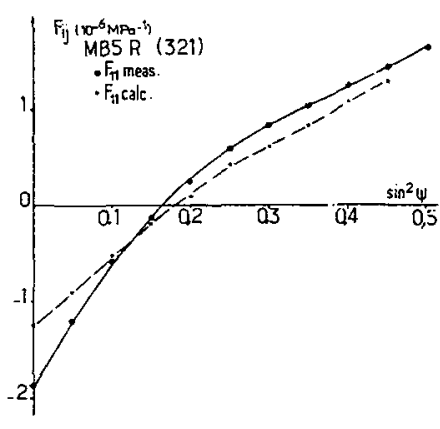

Figure 3: Calculated and measured XEC on (321) plane of a carbon steel using X ray synchrotron [3]

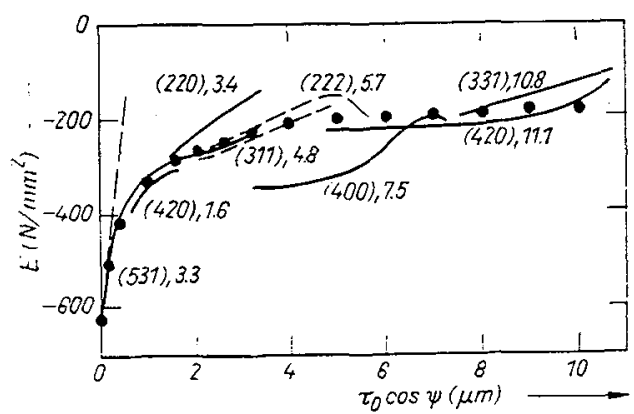

Figure 4: Residual stress gradient measurements on cold rolled Nickel on different planes [6].

An other application of synchrotron radiation is the crack tip stress distribution study [8], after a tensile overload. The mean difficulty is the diffracted surface studied, where the stress measurements are located in a small area at ahead of the crack tip. The X ray synchrotron, with its high intensity, allows to use an irradiated zone of about $0,15 \mathrm{~mm}$ in diameter, keeping a mean strain information on a large enough number of crystallites. The stress results have been shown close to the theoretical one performed by numerical finite element method.

The feasibility of a continuous wavelength change, its high intensity and high resolution are also of interest for multilayers thin films [9] where residual stresses can be determined in the coatings and the substrates. A typical application is needed in the case of different surface coating and treatments in order to enhance the friction or mechanical resistance and also electronic components. A recent application conducted at LURE Laboratory is the residual stress study on a Silver/Nickel multilayers ( 3 to 30 atomic planes for each layer) deposited by sputtering [10]. The total multilayer thickness was $5 \mu \mathrm{m}$. Some results have been reported and high compressive residual stresses have been measured (about $-3 \mathrm{GPa}$ ). These results are in interaction with the stresses in the substrate, as in composites.

\subsubsection{Second Order Stresses}

Many studies have been done in composites and two phase materials. The interests of synchrotron radiation is the wavelength variation and its high flux. Therefore it can be used in a case of stress gradient as in other materials listed above. The main problems associated to stress measurements in this kind of materials are (i) the presence of the $\sigma_{33}(\mathrm{z})$ component, which is not necessary zero contrary to single phase materials, and (ii) the low amount of the second phase contained. According to the method already described, the stress determined by $\sin ^{2} \psi$ law is $\left(\sigma_{\phi} \mathrm{e}-\sigma_{33} \mathrm{e}\right)$. Thus, calculating the stress in direction $\phi$ depends upon the $\sigma_{33}$ component. $\Omega$ and $\psi$ mode measurements have been performed by I. Detempler et al.[6] using synchrotron radiation on a ground steel plate on different crystallographic planes (321) and (211), assuming $\sigma_{33}=0$ for the $\Omega$ and $\psi$ mode. $16 \psi$-angles have been investigated up to $1.5^{\circ}$ and $0.65^{\circ}$ from the grazing incidence. For this two modes, the results shown on figure 5 indicate that the assumption of vanishing $\sigma_{33}$ was wrong. A new development has been proposed by the authors [6] to evaluate $\sigma_{33}$ variation in depth using experimental conditions given by synchrotron radiation.

Different categories of heterogeneous materials are studied by synchrotron radiation which provides high local resolution as well as high spectral resolution. An example is the IN-939 cast nickel-base superalloy, or structural hardening materials in general containing low amount of coherent or semi-coherent precipitates $(\gamma$, $\left.\gamma^{\prime}\right)[11,12]$. The stress determination difficulty is related to the near lattice parameter of the different phases, and the diffraction peaks are weak and close. For treating such peaks mathematical fitting have been proposed using for example Voigt or Pseudo-Voigt functions. A particularity of this cast nickel-base superalloy is its large grain size. For this, stresses have been measured during tensile stressing on the goniometer on a sample with a beam of about $250 \mu \mathrm{m} * 250 \mu \mathrm{m}$ on the surface. Figure 6 shows the stresses measured on three grains labelled $\mathrm{R}, \mathrm{P}, \mathrm{Q}$. The local stress components in tensile direction reveal stress 
inhomogeneities in the interior of grain, which are of the same magnitude as those found between adjacent grains.

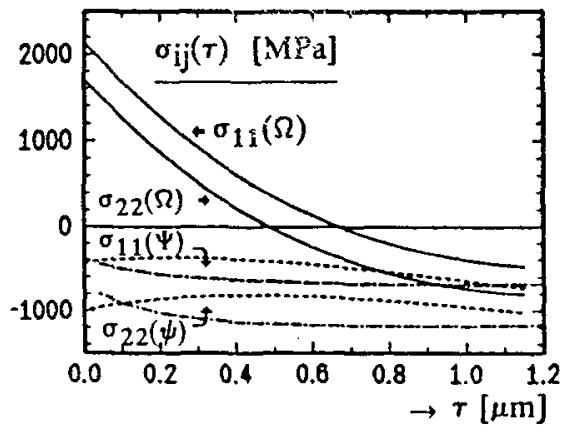

Figure 5: $\sigma_{11}(\tau)$ and $\sigma_{22}(\tau)$, calculated for $\sigma_{33}=0$ [4]. Full drawn lines: (211) $\Omega$-mode

Dashed lines: (211), $\Psi$-mode

Dashed dotted lines: EXRD resuits

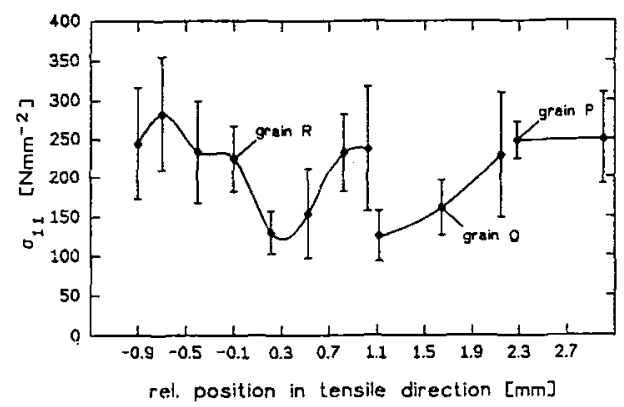

Figure 6: Local stresses within the grains $R, Q$ and $P$ at an external load of $240 \mathrm{~N} / \mathrm{mm}^{2}$ [11]

\subsubsection{Third Order Stresses:}

Analysis of the broadening of a diffraction peak allows the microstructure of a material to be characterized. The shape of a diffraction peak is the result of the convolution of the instrumental broadening depending on the $\mathrm{X}$ ray beam geometry and metallurgical effects which can be distinguished by the distribution of the crystallite size and the distribution of the lattice strains in each crystallite. After deconvolution of the instrumental broadening, the two effects are separated by pseudo-Voigt fitting. The use of synchrotron radiation is related to its high resolution as stated above. Several applications have been done mainly on cold rolled steels [3] and cold rolled aluminum as stated by $\mathrm{M}$. Belassel et al., the peak asymmetry can be used to relate the internal stresses with the dislocation arrangement during plastic deformation [13].

\subsection{Conclusion}

$\mathrm{X}$ ray diffraction method analysis has contributed strongly in the comprehension of the internal mechanisms which are responsible of the material mechanical behaviour. Macro and micro aspects studies are allowed by this technique, and this in a direct relation with the material development and its service condition. In order to improve the mechanical study of materials, as well as the development of new materials, fine microstructural characterizations are needed. For these investigations, the high resolution of Synchrotron radiation is an appropriate tool. As the matter of fact, at the present time more and more researchers are looking for this kind of technique.

\section{REFERENCES}

[1] G. Maeder, M. Barral, J.L. Lebrun and J.M. Sprauel, The Rigaku Journal, Vol.3, N² (1986) 9-20.

[2] G. Maeder, J.L. Lebrun and J.M. Sprauel, NDT International, October (1981) 235-247.

[3] M. Barral, J.L. Lebrun, J.M. Sprauel and G. Maeder, Metallurgical Transactions A Vol.18A, July

(1987) 1229-1237.

[4] M. Barral, J.M. Sprauel and S. Torbaty, Adv. in X ray Analysis, Vol. 26 (1983) 217-223.

[5] M. Barral, J.M. Sprauel and J.L. Lebrun, Advances in X ray Analysis, Vol. 27 (1984) 149-157.

[6] H. Ruppersberg, I. Detemple and J. Krier, Phys. Stat. sol. (a) Vol.116 (1989) 681-687.

[7] I. Detemple and H. Ruppersberg, Adv. in X ray Analysis, Vol. 37 (1994) (To be published)

[8] M.L. Busch and J.L. Lebrun, Journées Internationales de la SF2M, 15-17 Juin (1988), Paris

[9] T.J. Vink, M.A.J. Somers, J.L.C. Daamas and A.G.Dirks, J. appl. Phys., 70 (1991) 4301.

[10] K.F.Badawi, N. Durand, V. Pelosin, J.P. Lauriat and E. El-Kaïm, Bulletin du Cercle d'Etude des Métaux, 9ème colloque 17-18 Nov. 7, (1993) 24.1-24.4.

[11] H.A. Crostack and M. Wrobel, Proceeding of the ECRS3, Frunkfürt (1992) 791-796.

[12] W. Reimers, H.A. Crostack, M. Wrobel and G. Eckold, Nato Advanced Research Workshop, ARW900814, 18-22 March (1991), Oxford.

[13] M. Belassel, V. Ji, J.L. Lebrun, P. Gergaud, M. François and M. Bessière, This conference. 